\title{
Effect of Isosorbide Mononitrate and Misoprostol for Cervical Ripening in Induction of Labor
}

Moustafa Abbas Ibrahim, Hussein Mohammed Abdel Dayem, Amr Ahmed Abdelrhman, Doaa Hamed Abo El-Khir*

Department of Obstetrics and Gynecology, Faculty of Medicine, Zagazig University, Egypt

Corresponding Author: Doaa Hamed Abo El-Khir, Mobile: (+20)0111709 9679, Email: doaahamed699@gamil.com

\begin{abstract}
Background: Induction of labor has increased dramatically over the past two decades. Indications for induction of labor are either maternal (preeclampsia, pregnancy-induced hypertension) or fetal (post-term dates, growth retardation, ruptured membranes, diabetes). Objective: The purpose of this study was evaluation of the beneficial effect of isosorbide mononitrate and misoprostol for cervical ripening in induction of labor. Patients and Methods: A randomized clinical trial was carried out on 120 full-term pregnant women who were admitted for induction of labor in Zagazig University Hospitals in the period of July 2017 to March 2018. Patients were divided into two groups: Group A included 60 full term pregnant females who received $25 \mu \mathrm{g}$ misoprostol (Vagiprost tablet) and placebo tablet in the posterior vaginal fornix. Group B included 60 full-term pregnant females who received vaginal $25 \mu \mathrm{g}$ misoprostol (Vagiprost tablet) plus $40 \mathrm{mg}$ isosorbide mononitrate (Effox tablet) in the posterior vaginal fornix. Results: There was little difference between the effectiveness of vaginal $25 \mathrm{mg}$ misoprostol vaginal inserts and 40 $\mathrm{mg}$ isosorbide mononitrate vaginal inserts in induction of labor. The safety profiles of both drugs were similar, but isosorbide mononitrate administration is considered a low-risk method of labour induction for pregnant women at full term. Conclusions: The combination of misoprostol and isosorbide mononitrate may be more safe and effective for induction of cervical ripening in full-term pregnancy in comparison to misoprostol alone.
\end{abstract}

Key words: Cervical ripening, Induction of Labor, Isosorbide, Mononitrate, Misoprostol

\section{INTRODUCTION}

Induction of labor is defined as artificial initiation of labor before its spontaneous onset for the purpose of delivery of the fetoplacental unit. Labor induction is one of the most common procedures performed in obstetrics, reaching $10-20 \%$ of deliveries worldwide. The increasing rate of labor induction has probably played a role ${ }^{(\mathbf{1})}$.

Cervical ripening is the process of softening, shortening and partial dilatation of the cervix which takes place in days or weeks prior to the onset of labor. Considering uterine cervix characteristics, different methods have been used to improve its conditions prior to labor induction. In general, they could be divided into biochemical or mechanical, respectively corresponding to the use of pharmacological substance through different administration ways or to the use of devices crossing the cervical canal. For this reason, two other methods described, nipple stimulation and membranes stripping, could be considered mixed in the classification by mechanism of action ${ }^{(2)}$.

Isosorbide mononitrate (IMN) is a drug used principally in the treatment of angina pectoris and acts by dilating the blood vessels so as to reduce the blood pressure. IMN self-administered at home is safe and effective method for cervical ripening prior to induction of labor in women with term pregnancies as well as in outpatient setup ${ }^{(3)}$.

Misoprostol is a water-soluble, viscous liquid. Inactive ingredients of tablets are hydrogenated castor oil, hypromellose, microcrystalline cellulose, and sodium starch glycolate. Vaginal misoprostol is most commonly administered by placing a tablet in the posterior fornix of the vagina. Several studies have focused on the dose administered. Vaginal misoprostol in doses $25 \mu \mathrm{g}$ every 4 hours is more effective than conventional methods of labor induction (home like settings for child birth are associated with modest benefits including reduced medical intervention and increased maternal satisfaction), but with more uterine hyperstimulation ${ }^{(4)}$. This study aimed to evaluation of the beneficial effect of isosorbide mononitrate and misoprostol for cervical ripening in induction of labor.

\section{PATIENTS AND METHODS}

This study was carried out on 120 full- term pregnant women who were admitted for induction of labor in Zagazig University Hospitals in the period of July 2017 to March 2018.

\section{Ethical approval:}

The study was approved by the Ethics Board of Zagazig University and an informed written consent was taken from each participant in the study.

Sample size: Available resources and facilities (personal, equipment, time and money). Variability of the groups (only 2 groups) $\alpha$ error is $5 \%$ and confidence interval is $95 \%$, the estimated sample size was 120 cases.

Inclusion criteria: Singleton term pregnancies. Bishop's score $<6$. Full term pregnancy $>37$ weeks. Reassuring C.T.G.

Exclusion criteria: Patients with premature rupture of membranes. Multiple pregnancies. Polyhydramnios. 
Non cephalic presentation. Previous uterine scar. Cephalopelvic disproportion. Previous cervical operation.

All patients was subjected to full history with special emphases on LMP to determine the exact gestational age, abdominal examination, vaginal examination was done for all patients for evaluation of the Bishop's score by degree of cervical dilatation, degree of cervical effacement, degree of cervical consistency, cervical position, head station.

All patients were subjected for ultrasonography (U/S) to confirm estimated due date (EDD), number of fetuses, presenting part, amount of liquor, placental site and to exclude any abnormality. Non stress test (NST) to exclude fetal distress.

Patients were divided into two groups: Group A included 60 full term pregnant females who received $25 \mu \mathrm{g}$ misoprostol (Vagiprost tablet) and placebo tablet in the posterior vaginal fornix, and Group B included 60 full-term pregnant females who received vaginal 25 $\mu \mathrm{g}$ misoprostol (Vagiprost tablet) plus $40 \mathrm{mg}$ isosorbide mononitrate (Effox tablet) in the posterior vaginal fornix.

Evaluation of initial modified Bishop's score was done. Reevaluation of modified Bishop's score was done after 2, 4, 6, 8 hours respectively for cases with favorable cervices modified Bishop's score $>8$ with cervical dilatation $>3 \mathrm{~cm}$, artificial rupture of membranes (AROM) was done and according to presence or absence of meconium the following interventions were performed according to the hospital protocol and the following decisions were taken. If liquor showed clear (i.e., no meconium), start of induction of labor by oxytocin drip using titration method with fetal heart rate (FHR) monitoring if active labor was not spontaneously initiated after AROM by 1 hour. If liquor was thin meconium stained (i.e., mild degree), fetal heart rate monitoring was done for 30 minutes. If reassuring, proceed with oxytocin induction and fetal monitoring. If non-reassuring (i.e., variable decelerations), oxytocin induction was omitted and further assessment of fetal condition was done for possibility of cesarean section (CS). If deeply stained liquor (i.e., severe degree), cesarean section was done to avoid meconium aspiration syndrome.

\section{Oxytocin dose:}

Oxytocin infusion was given in the smallest possible volume, commencing at a rate of $1 \mathrm{mU} / \mathrm{min}$. Five units in $500 \mathrm{ml}$ of Ringer's solution were started. The infusion rate was increased (by doubling drops/min) at intervals of $30 \mathrm{~min}$, until there were 3-5 good contractions every 10 minutes each lasting 45-60 seconds. When 60 drops/min rate was reached with no efficient contractions, the infusion was replaced by 10 units oxytocin in $500 \mathrm{ml}$.

Partogrpahic assessment of uterine contractions every 1 hour and ensuring adequate uterine contractions (3-5 contractions in 10 minutes, every one lasts for 40-60 seconds) with detection of any abnormality as:

- Hypersystole: 1 uterine contraction with duration of more than 90 seconds.

- Tachysystole: 5 or more contractions in 10 minutes for 2 consecutive 10- minute period without FHR abnormalities.

- Hyperstimulation: as tachysystole associated with an abnormal FHR pattern.

Vaginal examination every two hours for assessment of cervical dilatation and effacement, head station, exclusion of passage of meconium, exclusion of signs of obstruction (cervical edema, diffuse caput).

Electronic fetal heart rate monitoring. Ensuring good fetal condition, if non-reassuring (i.e., variable or late decelerations), oxytocin was stopped, the patient was given intravenous fluids and oxygen mask (4-6 liters/min) and changed her position to the left lateral position. Adequate hydration analgesia was done using crystalloids and narcotics respectively if indicated. After delivery of the fetus, resuscitation and assessment of Apgar score after 1 minute and 5 minutes were done by the pediatrician.

\section{Statistical Analysis:}

Analysis of data was done by IBM computer using SPSS (statistical program for the social sciences version12). Chi-square test was used to compare qualitative variables between groups. Fisher exact test was used instead of chi-square when one expected cell or more $<5$. Paired and unpaired t-test was used to compare means as regard quantitative variable.

\section{RESULTS}

There was no statistically significant difference between both groups as regard demographic data.

Table (1): Comparison between both groups as regard demographic data

\begin{tabular}{|c|c|c|c||}
\hline Variables & $\begin{array}{c}\text { Group A } \\
\text { N=60 }\end{array}$ & $\begin{array}{c}\text { Group B } \\
\text { N=60 }\end{array}$ & P \\
\hline Maternal age (Mean \pm SD) & $26 \pm 4$ & $24 \pm 7$ & $>0.05$ \\
\hline Gestational age (Mean \pm SD) & $40.1 \pm 0.6$ & $41 \pm 0.7$ & $>0.05$ \\
\hline
\end{tabular}

This study showed statistically highly significant changes in modified Bishop's score compared to baseline result. There were 20 patients underwent CS, excluded from this table. 
Table (2): Changes in modified Bishop's score among misoprostol group

This study showed statistically highly significant changes in modified Bishop's score compared to baseline

\begin{tabular}{|c|c|c|c|c|}
\hline Modified Bishop's score & $\begin{array}{c}\text { Mean } \\
\mathbf{N = 4 0}\end{array}$ & $\mathbf{\pm S D}$ & \% of change & $\mathrm{p}$ \\
\hline Initial score & 2.8 & 0.7 & & \\
\hline After 2 hours & 3.9 & 1.8 & $32 \%$ & $<0.05$ \\
\hline After 4 hours & 4.1 & 2 & $50 \%$ & $<0.01$ \\
\hline After 6 hours & 5.1 & 1.5 & $59 \%$ & $<0.01$ \\
\hline After 8 hours & 5.9 & 2.3 & $78 \%$ & $<0.01$ \\
\hline
\end{tabular}

result. There were 18 patients underwent CS, excluded from this table (18 or 20 were excluded).

Table (3): Changes in Bishop's score among misoprostol plus IMN group

\begin{tabular}{|c|c|c|c|c|}
\hline Modified Bishop's score & $\begin{array}{c}\text { Mean } \\
\mathbf{N = 4 0}\end{array}$ & $\mathbf{\pm S D}$ & \% of change & $\mathrm{p}$ \\
\hline Initial score & 3.3 & 0.8 & & \\
\hline After 2 hours & 4.6 & 1.8 & $21 \%$ & $<0.05$ \\
\hline After 4 hours & 5.8 & 2 & $27 \%$ & $<0.01$ \\
\hline After 6 hours & 6.6 & 3 & $69 \%$ & $<0.01$ \\
\hline After 8 hours & 7.8 & 2.3 & $96 \%$ & $<0.01$ \\
\hline
\end{tabular}

This study showed that modified Bishop's score was higher among group B compared to group A with highly significant difference in between. There were 20 and 18 patients from group A and B respectively underwent CS, excluded from this table.

Table (4): Comparison between both groups as regard modified Bishop's score

\begin{tabular}{|c|c|c|c|}
\hline Modified Bishop's score & $\begin{array}{c}\text { Group A } \\
\mathbf{N = 4 0}\end{array}$ & $\begin{array}{c}\text { Group B } \\
\mathbf{N = 4 2}\end{array}$ & $\mathbf{p}$ \\
\hline Initial score & $2.8 \pm 0.7$ & $3.3 \pm 0.8$ & $>0.05$ \\
\hline After 2 hours & $3.9 \pm 1.8$ & $4.6 \pm 1.8$ & $>0.05$ \\
\hline After 4 hours & $4.1 \pm 2$ & $5.8 \pm 2$ & $<0.001$ \\
\hline After 6 hours & $5.1 \pm 1.5$ & $6.6 \pm 3$ & $<0.001$ \\
\hline After 8 hours & $5.9 \pm 2.3$ & $7.8 \pm 2.3$ & $<0.001$ \\
\hline
\end{tabular}

This study showed that group B had a shorter time in comparison to group A with statistically significant difference by using unpaired t-test. There were 20 and 18 patients from group A and B respectively underwent CS, excluded from this table.

Table (5): Comparison between both groups as regard time from given dose to beginning of active phase and vaginal delivery

\begin{tabular}{|l|c|c|c|}
\hline \multicolumn{1}{|c|}{$\begin{array}{c}\text { Time from given misoprostol alone or with } \\
\text { IMN (hours) }\end{array}$} & $\begin{array}{c}\text { Group A } \\
\mathbf{N = 4 0}\end{array}$ & $\begin{array}{c}\text { Group B } \\
\mathbf{N}=\mathbf{4 2}\end{array}$ & $\mathbf{p}$ \\
\hline Time until active phase of labor & $6.3 \pm 2$ & $4.5 \pm 2$ & $<0.05$ \\
\hline $\begin{array}{l}\text { Time until vaginal delivery from the start of } \\
\text { cervix ripening }\end{array}$ & $6.2 \pm 1.6$ & $6 \pm 1.4$ & $>0.05$ \\
\hline $\begin{array}{l}\text { Time until vaginal delivery from the start of } \\
\text { induction }\end{array}$ & $12.5 \pm 5$ & $10.5 \pm 3.6$ & $<0.05$ \\
\hline
\end{tabular}

This study showed that headache was more common among group B with significant difference. 
Table (6): Comparison between both groups as regard side effects

\begin{tabular}{|c|c|c|c|}
\hline Variables & $\begin{array}{c}\text { Group A } \\
\mathbf{N = 6 0}\end{array}$ & $\begin{array}{c}\text { Group B } \\
\mathbf{N = 6 0}\end{array}$ & P \\
\hline Fever & $5(8.3 \%)$ & $3(5 \%)$ & $>0.05$ \\
\hline Hot flushes & $5(8.3 \%)$ & $6(10 \%)$ & $>0.05$ \\
\hline Palpitations & $4(6.7 \%)$ & $7(11.7 \%)$ & $>0.05$ \\
\hline Nausea & $8(13.3 \%)$ & $6(10 \%)$ & $>0.05$ \\
\hline Headache & $20(33.3 \%)$ & $30(50 \%)$ & $>0.05$ \\
\hline Vomiting & $3(5 \%)$ & $4(6.7 \%)$ & $>0.05$ \\
\hline Diarrhea & $2(3.3 \%)$ & $3(5 \%)$ & $>0.05$ \\
\hline Cases free & $13(21.6 \%)$ & $12(20 \%)$ & $>0.05$ \\
\hline
\end{tabular}

This study showed that no statistically significant difference could be detected between both groups.

Table (7): Comparison between both groups as regard uterine contraction abnormalities

\begin{tabular}{|c|c|c|c|}
\hline Uterine contraction abnormalities & $\begin{array}{c}\text { Group A } \\
\text { N=60 }\end{array}$ & $\begin{array}{c}\text { Group B } \\
\mathbf{N = 6 0}\end{array}$ & $\mathrm{p}$ \\
\hline Tachysystole & $6(10 \%)$ & $5(8.33 \%)$ & $>0.05$ \\
\hline Hypersystole & $1(1.6 \%)$ & $2(3.3 \%)$ & $>0.05$ \\
\hline Hyperstimulation & $1(1.6 \%)$ & $0(0.0 \%)$ & $>0.05$ \\
\hline
\end{tabular}

There was a minimal difference in fetal heart rate abnormalities and meconium passage with no statistically significant difference in between. Cesarean section was done to these cases because of their persistence.

Table (8): Comparison between both groups as regard intrapartum fetal monitoring

\begin{tabular}{|c|c|c|c|}
\hline Fetal monitoring & $\begin{array}{c}\text { Group A } \\
\text { N=60 }\end{array}$ & $\begin{array}{c}\text { Group B } \\
\text { N=60 }\end{array}$ & $\mathrm{p}$ \\
\hline \multirow{2}{*}{ Heart rate abnormalities } & $\begin{array}{c}6 \\
(10 \%)\end{array}$ & $\begin{array}{c}7 \\
(11.6 \%)\end{array}$ & $>0.05$ \\
\hline \multirow{2}{*}{ Meconium passage } & $\begin{array}{c}5 \\
(8.3 \%)\end{array}$ & $(6.7 \%)$ & $>0.05$ \\
\hline
\end{tabular}

This study showed that no statistically significant difference between both groups.

Table (9): Comparison between both groups as regard mode of delivery

\begin{tabular}{|c|c|c|c|}
\hline Mode of delivery & $\begin{array}{c}\text { Group A } \\
\mathbf{N = 6 0}\end{array}$ & $\begin{array}{c}\text { Group B } \\
\mathbf{N = 6 0}\end{array}$ & P \\
\hline VD & $\begin{array}{c}39 \\
(65)\end{array}$ & $\begin{array}{c}40 \\
(66.66 \%)\end{array}$ & $>0.05$ \\
\hline \multirow{2}{*}{ Assisted VD } & $\begin{array}{c}1 \\
(1.66 \%)\end{array}$ & $(3.3 \%)$ & $>0.05$ \\
\hline Cesarean section & $\begin{array}{c}20 \\
(33.3 \%)\end{array}$ & $\begin{array}{c}18 \\
(30 \%)\end{array}$ & $>0.05$ \\
\hline
\end{tabular}

This study showed that no statistically significant difference could be detected between both groups. All undelivered women who weren't in active labor (regular contraction every 10 minutes lasting 1minute, or a change in Bishop's score of at least 4 points), were considered a treatment failure in 18 hours.

This study showed that combination group B had a higher Apgar score 1 minute and 5 minute with statistically significant difference between both groups by using unpaired t-test. 
Table (10): Comparison between both groups as regard indications of CS and neonatal outcome

\begin{tabular}{|c|c|c|c|}
\hline & Group A N=20 & Group B N=18 & P \\
\hline CS indications & & 10 & \\
\hline Fetal distress & $\begin{array}{c}11 \\
(55 \%)\end{array}$ & $(55.55 \%)$ & $>0.05$ \\
\hline Arrested of cervical dilatation & $\begin{array}{c}5 \\
(27,77)\end{array}$ & $>0.05$ \\
\hline Failure of induction & $\begin{array}{c}3 \\
(16.66 \%)\end{array}$ & $>0.05$ \\
\hline Apgar 1minute & $5.3 \pm 2$ & $6.8 \pm 1.9$ & 2.2 \\
\hline Apgar 5 minute & $7.2 \pm 2$ & $8.6 \pm 1.4$ & 2.6 \\
\hline
\end{tabular}

*Arrested of cervical dilatation: failure to dilate in active labor for greater than or equal 1 hour to 2 hours

\section{DISCUSSION}

In our study, patients characteristics in both groups were similar as regard maternal age, gestational age and parity. This result coincided with Abdellah et $\boldsymbol{a l} .{ }^{(5)}$ who evaluated the efficacy and safety of intra-vaginal administration of nitric oxide (NO) donor isosorbide mononitrate plus misoprostol versus, misoprostol for cervical ripening and induction of labour and found that these results were higher in glyceryl trinitrate (GTN) group but did not reach the level of statistical significance. Elsokary $\boldsymbol{e t} \boldsymbol{a l}{ }^{(\boldsymbol{6})}$ evaluated the safety and effectiveness of adding isosorbide mononitrate to misoprostol for cervical ripening in prelabor induction of full term pregnant women in comparison with misoprostol alone. They showed that there is no statistical significant difference between the two groups (group I given intravaginal isosorbide mononitrate with misoprostol and group II given placebo with misoprostol intravaginally) as regards mean age and gestational age.

As regard modified Bishop's score, there were statistically highly significant changes in modified Bishop's score compared to baseline result among vagiprost group. Calder et al. $^{(7)}$ showed that 25microgram vaginal misoprostol tablet provides an effective and well tolerated option for cervical ripening and labor induction. MacKenzi et al. ${ }^{(8)}$ showed that IMN by it's inflammatory mechanism involving vasodilatation, altered vascular permeability and neutrophils influx into cervical tissues; these lead to cervical ripening and changes in cervical consistency. Abdellah et al $^{\left({ }^{(5)}\right.}$ studied two hundred and ninety women scheduled for labor induction, assigned randomly to IMN or placebo followed by misoprostol $50 \mu \mathrm{g}$. The efficacy of the medication was evaluated by predetermined outcome variables for cervical ripening and induction of labor and delivery. The two groups were comparable with respect to age, parity, gestational age, indication for induction, and Bishop's score. Women receiving IMN plus misoprostol showed significant changes in the Bishop score 6 hours after administration as compared to misoprostol plus placebo. Sherif et al. ${ }^{\left({ }^{(9)}\right.}$ found that the mean initial modified Bishop's score was 2.8 then Bishop's score became 3.9, 4.1, 5.1, 5.9 after 2, 4, 6, 8 hours, respectively indicating significant improvement in the modified Bishop's score. This improvement may be related either to the inflammatory mechanisms associated with IMN involving vasodilatation, or to altered vascular permeability and neutrophils influx into cervical tissues leading to cervical ripening and changes in cervical consistency, but these findings disagreed with Bollapragada et $\boldsymbol{a l} .{ }^{(\mathbf{1 0})}$ who failed to demonstrate an improvement in the mean Bishop's score following IMN despite showing clinical effectiveness in shortening labor, also disagreed with Nunes et al. ${ }^{(11)}$. This may be due to different type and dose of misoprostol and IMN to this study.

Elsokary et al. ${ }^{(6)}$ showed that there was no statistical significant difference between the two groups as regards mean initial Bishop's score. There was a higher Bishop's score after 6 hours among cases in group I (given intravaginal isosorbide mononitrate with misoprostol) compared to cases in group II (given placebo with misoprostol intravaginally) and the difference was statistically significant. There was no statistical significant difference between the two groups as regards the Apgar score at 1 and 5 minutes.

In this study as regard the time from given dose to beginning of active phase, group B had a shorter time in comparison to group A with statistically significant difference. Wolfer et al $^{\left({ }^{(12)}\right.}$ studied 120 nulliparas women at term for induction of labor for various obstetric indications, they were randomly assigned to receive per-vaginum $40 \mathrm{mg}$ isosorbide mononitrate (ISMO) or placebo in addition to $3 \mathrm{mg}$ dinoprostone 2 times daily for up to 2 days. They found that there was no significant statistical difference between both groups regarding the mean time from initial dose to beginning of active phase of labor and to delivery. These results agreed with Nunes et al. ${ }^{(11)}$ who reported that the association of NO donor glyceryl trinitrate $(\mathrm{GTN})(5 \mathrm{mg} / \mathrm{kg})$ with dinoprostone $(2 \mathrm{mg})$ was more effective than dinoprostone alone for 
cervical ripening and labor induction at term. However, Chanrachakul et al. ${ }^{\left({ }^{(13)}\right.}$ had found the time from start of medication to vaginal delivery in IMN group was significantly longer. Also, these results agreed with Nunes $\boldsymbol{e t}$ al. ${ }^{(11)}$, who reported that the association of NO donor glyceryl trinitrate (GTN) (500 $\mathrm{mg} / \mathrm{kg}$ ) with dinoprostone $(2 \mathrm{mg}$ ) was more effective than dinoprostone alone for cervical ripening and labor induction at term. Elsokary et al. ${ }^{(6)}$ showed that there was a shorter duration of the active phase of delivery and labor in group I (given placebo with misoprostol intravaginally) compared to group II (given intravaginal isosorbide mononitrate with misoprostol) and the difference was highly significant.

These findings disagreed with Wolfler et al. ${ }^{(12)}$, who showed that vaginal application of IMN plus dinoprostone appeared to be no more effective than placebo plus dinoprostone for cervical ripening and labor induction at term suggesting a different effectivity of IMN depending on the gestational age in this study. Also, these results disagreed with Collingham et al. ${ }^{(14)}$, who reported that, the time from start of induction to vaginal delivery not reduced when IMN was added to misoprostol, might be due to the relaxing effect of IMN on the uterine fundus. The findings could possibly be explained by the differences in parity of patients, mean gestational age at delivery and the indication for the induction of labor.

Abdellah et al. ${ }^{(5)}$ found that significantly shorter intervals of IMN group than of placebo group from the beginning of the induction to the beginning of the active phase of labor and from the beginning of induction to the time of delivery. They found a significantly shorter intervals in IMN plus misoprostol group from the beginning of the induction to the beginning of the active phase of labor and from the beginning of induction to the time of delivery.

In this study, headache was more common among group $\mathrm{B}$ with significant difference. Collingham et al. ${ }^{(14)}$ found that headache of mild to moderate intensity affects 32 out of 55 women (58.2\%). Although headache was reported by about one third of women in the isosorbide mononitrate group, only 3 described headache as having an intensity of 7 on a visual analog scale between 0 and 10. This may be due to that only one dose of IMN was used. None of the women needed any kind of medical therapy because of the reported side effects including headache. This study agreed by Wolfler $\boldsymbol{e t} \boldsymbol{a l} .^{(\mathbf{1 2})}$ who explained that vasodilatation effect of (NO) donors causes headache. But, Cunningham et al. ${ }^{(15)}$ found that the addition of vaginal isosorbide mononitrate to oral misoprostol for cervical ripening and labor induction did not reduce time to vaginal delivery and was associated with a greater incidence of headache, this negative finding may be due to use of oral misoprostol instead of vaginal misoprostol to eliminate the pharmacologic interaction between vaginal misoprostol and vaginal isosorbide mononitrate; however, the lack of effect of the oral form on cervical tissue may explain the negative findings. Elsokary $\boldsymbol{e} t$ al. ${ }^{(6)}$ showed that there was nausea and shivering in group II compared to group I but the difference was not statistically significant. There was a higher incidence of side effects and headache in group I compared to group II and the difference was statistically significant. There was no statistical significant difference between the two groups as regards the incidence of postpartum hemorrhage $(\mathrm{PPH})$ or retained placenta. There was no need for ICU admission.

This study found no significant difference between 2 groups in the incidence of uterine hypersystole, tachysystole and hyperstimulation. But these results disagreed with similar study ${ }^{(14)}$, which had found that GTN is safer, but less effective, compared with prostaglandins for pre induction cervical ripening at term. This study agreed with Abdellah et $\boldsymbol{a l} .{ }^{(5)}$ as they found also that there was no significant difference in the incidence of uterine hypersystole, tachysystole or hyperstimulation. Also, Elsokary $\boldsymbol{e t} \boldsymbol{a l} .{ }^{(\boldsymbol{6})}$ showed that higher percentage of uterine contraction abnormalities in group I 15\% compared to $11.7 \%$ in group II but the difference is not statistically significant.

In this study, there was a minimal difference in fetal heart rate abnormalities and meconium passage with no statistically significant difference in between. That is because the mechanism of action of misoprostole and NO donor is different and their combined use may be synergistic and lead to more effective cervical ripening. At the same time, they have an antagonistic effect in the myometrium that is stimulated by prostaglandins and relaxed by $\mathrm{NO}$ donors resulting in less frequent episodes of tachysystole.

Chanrachakul et $\boldsymbol{a l} .^{\left({ }^{(13)}\right.}$ found that dystocia was more frequent in IMN $9(45 \%)$ versus, $6(37.5 \%)$ in misoprostol group while non-reassuring FHR in IMN group was $3(15 \%)$ versus, $9(56.3 \%)$ in misoprostol group.

As regard the mode of delivery, cesarean delivery had emerged in $20(33.3 \%)$ in the misoprostol group and $18(30 \%)$ in isosorbide mononitrate group, this difference was statistically insignificant. This result agreed with Cunningham et al ${ }^{(15)}$ who found that there was no significant statistical difference between both groups regarding the mode of delivery. Elsokary et al. ${ }^{(6)}$ showed that there was a higher percentage of C.S delivery in group II compared to group I but the difference was not statistically significant.

In this study, no statistically significant difference could be detected between both groups as 
regard indications of CS, but there was statistically significant difference between both groups as regard neonatal outcome (Apgar score at one minute and 5 minutes). Elsokary et al. ${ }^{(6)}$ showed that there was no significant difference between the two groups as regards the indication of C.S.

We can say that the better patients acceptability although uterine hyperstimulation and meconium staining the main concern with misoprostol use, close maternal-fetal miniaturization and timely intervention measures would prevent devastating adverse effects during labor induction and increase tolerability of the drug by mother and fetus.

Ekerhovd et al. (16) found that vaginal administration of $40 \mathrm{mg}$ of isosorbde mono-nitrate induces cervical ripening at term. Collingham et al. ${ }^{\left({ }^{14}\right)}$ postulated that a combination between misoprostol and IMN might improve induction success rates while reducing side effects associated with misoprostol. Abdellah et al.$^{(5)}$ concluded that using a combination of IMN and misoprostol is effective than misoprostol alone in terms of fast cervical ripening and shortening of induction-labor interval. Meena et al. ${ }^{(3)}$ evaluated the efficacy and safety of isosorbide mononitrate for cervical ripening prior to induction of labor at term pregnancy in an outpatient setting in India. They concluded that IMN self-administered at home is safe and effective method for cervical ripening prior to induction of labor in women with term pregnancies..

\section{CONCLUSIONS}

The combination of misoprostol and isosorbide mononitrate may be more safe and effective for induction of cervical ripening in full-term pregnancy in comparison to misoprostol alone.

\section{REFERENCES}

1. Guerra G, Cecatti J, Souza J et al. (2015): Factors and outcomes associated with the induction of labour in Latin America. BJOG., 116: 1762-72.

2. Hofmeyr G (2014): Induction and augmentation of labour. In: Edmond IK (ed): Dewhurst's Textbook of Obstetrics and Gynaecology; seventh edition. Oxford, UK: Blackwell Publishing. Pp. 205-212.

3. Meena N, Binda N, Meena S (2016): Evaluation of isosorbide mononitrate for cervical ripening prior to induction of labor at term pregnancy in an outpatient setting. Int J Reprod Contracept Obstet Gynecol., 5(3): 793-797.
4. Hodnett E, Down S, Edwards N et al. (2005): Home_like versus conventional institutional setting for birth. Cochrane Database Syst Rev., (1):CD000012.

5. Abdellah M, Hussien M, AboAlhassn A (2010): Intravaginal administration of IMN and misoprostol for cervical ripening and induction of labor. Arch Gynaecol Obstet., 284: 1: 25-30.

6. Elsokary M, Abdelhamed M, Mohamad E (2015): Isosorbide mononitrate and misoprostol for cervical ripening in induction of labor. Gynecology and Obstetrics, 15(4): 2249-46181.

7. Calder A, Loughney A, Weir C (2008): Induction of labor with low dose misoprostol. BJOG., 115: 1279-1288.

8. MacKenzi F, Norrie J, Murray H et al. (2006): The "PRIM" study: A randomized comparison of prostaglandin E2 gel with a nitric oxide donor Isosorbidemononitrate for cervical ripening before induction of labor at term: a randomized controlled study. Am J Obstet Gynceol., 194(4): 1012-21.

9. Sherif H, Ahmed M, Amgad A (2009): comparison between misprostol and isopronide mononitrate and misoprostol in preinduction cervical repair. Obstet Gynecol., 35: 258-3216.

10. Bollapragada S, Mackenzie F, Norrie J et al. (2009): Randomized placebo-controlled trial of outpatient (at home) cervical ripening with isosorbide mononitrate (IMN): The IMOP study. Br J Obstet Gynecol., 116(9): 1185-95.

11. Nunes F, Campos A, Pedroso S et al. (2006): Intravaginal glyceryl trinitrate and dinoprostone for cervical ripening and induction of labor. Am J Obstet Gynecol., 194(4): 1022-6.

12. Wolfer M, Facchinetti F, Venturini $V$ et al. (2006): Induction of labor at term using Isosorbidemononitrate simultaneously with dinoprostone compared to dinoprostone alone .Am J Obstet Gynecol., 195:1617-22.

13. Chanrachakul B, Herabutya $Y$, Punyavachira $P$ (2000): Randomized comparison of glyceryl trinitrate and prostaglandin E2 for cervical ripening at term. Obstet Gynecol., 96: 549-553.

14. Collingham J, Fuh K, Caughey A (2010): Oral misoprostol and vaginal isosorbide mononitrate for labor induction: a randomized controlled trial. Obstet Gynecol., 116(1): 121-6

15. Cunningham $F$, Leveno $K$, Bloom $S$ et al. (2005): Williams Obstetrics, $22^{\text {nd }}$ edn. The McGraw Hill Companies, USA, Pp. 535-545. https://www.scirp.org/(S(vtj3fa45qm1ean45vvffcz55))/ref erence/ReferencesPapers.aspx?ReferenceID $=1409850$

16. Ekerhovd E, Bullarbo M, Andersch B et al. (2003): Vaginal administration of the nitric oxide donor isosorbide mononitrate for cervical ripening at term: A randomized controlled study. Am J Obstet Gynecol., 189(6): 16921697. 